\title{
Uma mulher "recatada": a deputada Suely de Oliveira (1950-1974)
}

Céli Regina Jardim Pinto*

\section{RESUMO}

O personagem central deste artigo é Suely de Oliveira, a primeira deputada estadual eleita no Estado do Rio Grande do Sul em 1950 e reeleita cinco vezes, e que por 16 anos foi a única mulher no parlamento gaúcho. Tem como objetivo analisar as condições do exercício de seus mandatos a partir do exame de sua condição de mulher, do efeito que causou na relação com os demais deputados e da forma como ela própria se via como mulher. Essas questóes serão examinadas a partir de uma perspectiva teórica, que discute a importância da presença das mulheres na política e na luta pelos direitos das mulheres e outras minorias. $\mathrm{O}$ artigo está dividido em duas partes: na primeira apontará, ainda que rapidamente, um conjunto de questóes teóricas que embasam a análise da presença das mulheres na política; na segunda parte, será examinada a trajetória de Suely na Assembleia Legislativa.

Palavras-chave: história das mulheres; relaçôes de gênero; história do Rio Grande do Sul; teoria feminista; participação política.

\section{ABSTRACT}

The main character of this paper, Suely Oliveira, was the first woman elected state representative in the State of Rio Grande do Sul in 1950. Re-elected five times, for 16 years she remained the only woman in the Gaucho Parliament. This paper aims to analyze the conditions surrounding her mandates by examining her womanhood, the effect caused by it in her relationship to other representatives, and the way she saw herself as a woman in this scenario. These issues will be approached from a theoretical perspective, which discusses the importance of the presence of women in politics and the struggle for the rights of women and other minorities. The article has two sections: the first points out, albeit briefly, a set of theoretical issues that underlie the analysis of the presence of women in politics; the second examines the trajectory of Oliveira in the State Assembly.

Artigo recebido para publicação em 27 de janeiro de 2014 e aprovado em 28 de julho de 2014.

* Doutora em Ciência Política pela University of Essex, Inglaterra, e professora associada IV. Professora associada IV da Universidade Federal do Rio Grande do Sul (UFRGS). Porto Alegre, RS, Brasil. E-mail: celirjp@gmail.com.br. 
Keywords: History of women; relations of gender; History of Rio Grande do Sul; Feminist Theory; political participation.

No ano de 1950 o Rio Grande do Sul elegeu a sua primeira deputada: Suely de Oliveira foi eleita deputada estadual pelo PTB. A segunda mulher a ser eleita deputada no estado foi Terezinha Irigaray, 16 anos depois. Suely se reelegeu por cinco legislaturas, deixando o legislativo em 1974. ${ }^{1}$ A trajetória desta deputada se reveste de importância e excepcionalidade, em primeiro lugar porque foi a primeira mulher eleita e por longos anos manteve-se como a única na Assembleia Legislativa. Em segundo, porque a ausência das mulheres nas casas legislativas no Brasil e no mundo tem sido uma das questóes mais analisadas e estudadas pelos estudos de gênero e pela própria militância feminista, ${ }^{2}$ daí a importância de uma presença excepcional.

Após décadas de feminismo no mundo ocidental o campo em que a mulher menos avançou em termos de participação foi o da política. Mesmo nos Estados Unidos, na Inglaterra e na França, países de democracias maduras e onde o feminismo teve uma grande presença a partir de 1970 , as mulheres ainda estáo longe de alcançar $50 \%$ dos assentos parlamentares. ${ }^{3} \mathrm{O}$ Brasil tem uma posição particularmente pobre no que diz respeito à participação política das mulhe-

\footnotetext{
${ }^{1}$ Suely de Oliveira faleceu em 1994. Nos últimos 20 anos de sua vida afastou-se completamente da política. ${ }^{2}$ A análise da política estadual reveste-se de especial importância no estudo da história da participação política da mulher no Brasil, na medida em que é um espaço intermediário entre a política local, onde aparece o maior número de mulheres eleitas, e a grande política, onde o número de mulheres eleitas tem sido muito pequeno. No espaço regional encontramos um mundo da política já mais sofisticado, com questôes partidárias mais fortes em relação a questôes de compadrio da política municipal, com problemas políticos complexos como do próprio funcionalismo público, que foi tema preferencial da deputada analisada aqui. Já existem trabalhos importantes sobre a política local e estadual no Brasil, mas poucos com uma perspectiva histórica. Entre esses trabalhos destacam-se: ÁLVARES, Maria Luzia Miranda. Mulheres brasileiras em tempo de competição eleitoral: seleção de candidaturas e degraus de acesso aos cargos parlamentares. DADOS - Revista de Ciências Sociais, Rio de Janeiro, v. 51, n. 4, p. 895-940, 2008; ARAÚJO, Clara. Potencialidades e limites da política de cotas no Brasil. Revista de Estudos Feministas, Florianópolis, v. 9, n. 1, p. 231-252, 2001; ARAÚJO, Clara. Partidos políticos e gênero: mediaçóes nas rotas de ingresso das mulheres na representação política. Revista Sociologia e Politica, Curitiba, v. 24, p. 193-215, jun. 2005; ARAÚJO, Clara. Gênero e acesso ao poder legislativo no Brasil: as cotas entre as instituiçôes e a cultura. Revista Brasileira de Ciência Politica, Brasília, n. 2, p. 23-59, jul./dez. 2009; AVELAR, Lúcia. Mulheres na elite política brasileira: canais de acesso ao poder. São Paulo: Fundação Konrad Adenauer, 2001; MIGUEL, Luis Felipe. Teoria política feminista e liberalismo: o caso das cotas de representação. Revista Brasileira de Ciências Sociais, v. 15, n. 44, p. 91-102, out. 2000; MIGUEL, Luis Felipe. Política de interesses, política do desvelo: representação e "singularidade feminina”. Estudos Feministas, Florianópolis, p. 253-267, jan. 2001; MIGUEL, Luis Felipe; BIROLI, Flávia. Práticas de gênero e carreiras políticas: vertentes explicativas. Estudos Feministas, Florianópolis, v. 18, n. 3, p. 653-679, set./dez. 2010.

${ }^{3}$ Nos Estados Unidos, as mulheres são 16,8\% dos deputados federais e 17\% dos senadores; na Inglaterra, são 18,9\% do parlamento; e na França, 10,8\%. Disponível em: <http://www.brasil.gov.br/secoes/mulher/ atuacao-feminina/mulheres-na-politica>. Acesso em: $27 \mathrm{dez} .2012$.
} 
res, ocupa a posição 110 entre 147, segundo dados da União Parlamentar. Na atual legislatura (2010-2014) as mulheres representam 8,6\% dos deputados federais e $16 \%$ dos senadores. ${ }^{4}$

Nas Assembleias Legislativas no Brasil o quadro não é diferente. Avelar traz dados reveladores para as eleiçóes em que Suely de Oliveira elegeu-se:

Tabela 1

Presença das mulheres nas Assembleias Legislativas dos estados (1950-1970)

\begin{tabular}{|c|c|c|}
\hline ano & candidatas & eleitas \\
\hline 1950 & 10 & 8 \\
\hline 1954 & 15 & 7 \\
\hline 1958 & 39 & 2 \\
\hline 1962 & 92 & 11 \\
\hline 1965 & 39 & 11 \\
\hline 1970 & 38 & 8 \\
\hline
\end{tabular}

Fonte: AVELAR, Lúcia. As mulheres na elite politica Brasileira. São Paulo: Fundação Konrad Adenauer, 2001. p. 64

No Estado do Rio Grande do Sul a situação não é diferente: de 1951 a 2010 (data da última eleição legislativa) elegeram-se para a Assembleia Legislativa do Rio Grande do Sul 23 mulheres (houve mais quatro mulheres que assumiram como suplentes por curtos períodos de tempo). Essas mulheres tiveram 30 mandatos ao longo de 16 legislaturas, em um total de 877 mandatos. ${ }^{5}$ Portanto, de 1951, quando foi eleita a primeira mulher deputada, até 2010, as mulheres representaram $3,38 \%$ mandatos.

Este artigo tem como personagem central Suely de Oliveira, mas não pretende fazer uma biografia da deputada, e sim analisar as condiçôes do exercício de seus mandatos a partir do exame de sua atuação como deputada, do efeito que causou na relaçáo com os demais deputados, a forma como ela própria se via como mulher. Essas questóes serão analisadas a partir de uma perspectiva teórica que discute a importância da presença das mulheres na política na luta pelos direitos das mulheres e de outras minorias.

$\mathrm{O}$ artigo está dividido em duas partes: a primeira apontará, ainda que rapidamente, um conjunto de questôes que embasam a análise da presença das mulheres na política. $\mathrm{Na}$ segunda parte será examinada a trajetória de Suely de Oliveira na Assembleia Legislativa.

\footnotetext{
${ }^{4}$ INTER-PARLIAMENTARY UNION. Women in national parliaments. Disponível em: <http://www.ipu. org/wmn-e/classif.htm>. Acesso em: 10 dez. 2012.

${ }_{5}^{5}$ ASSEMBLEIA LEGISLATIVA DO RIO GRANDE DO SUL. Informaçôes Parlamentares/Legislaturas. In: Memorial do Legislativo do Rio Grande do Sul. Disponível em: <http://www2.al.rs.gov.br/memorial/> Acesso em: 20 dez. 2012.
} 


\section{Considerações a propósito da participação política da mulher}

Três teóricas do feminismo com perspectivas muito distintas têm trabalhos de grande repercussão sobre a relação entre defesa dos direitos das mulheres e a participação política das mesmas: Anne Phillip e Iris Young e a filósofa Judith Butler.

Anne Phillip discutiu largamente a diferença entre a ideia (defesa de interesses de um grupo) e a presença no parlamento do grupo, quando tratou da participaçáo política das mulheres e de outros grupos excluídos. Admite que possa haver uma sem a outra, mas que a presença dos excluídos potencializa a possibilidade da ideia. Em outras palavras, a defesa do direito das mulheres pode ser feita sem a presença delas nos parlamentos, mas a possibilidade que isto aconteça é muito pequena, o que leva Phillips a defender o aumento do número de mulheres nos parlamentos:

Nós temos nos tornado suficientemente afinados com a política de presença para desconfiar da noção de que qualquer um pode estar no lugar de qualquer outro e suficientemente alerta para os poderes coercitivos da homogeneidade para querer refletir a diversidade. ${ }^{6}$

Phillip não resolve a questáo da representaçáo simplesmente com a defesa da presença das mulheres, pois reconhece que as mulheres chegam à posição de poder político não necessariamente porque se colocaram no mundo político como mulheres. Daí não haver razão para esperar que no exercício de seus mandatos tornem-se defensoras dos direitos femininos. Phillip identifica que há contextos coercitivos que diluem as identidades anteriores fazendo com que grupos até então excluídos, quando chegam ao poder, tenham de negociar esta posição de forma tal, a ponto de náo conseguirem representar a "ideia" que os levaram a lutar pela posiçáa. Ainda discutindo o binômio ideia/presença, Phillip se pergunta: "Podem asiáticos ser representados por afro-caribenhos, hindus por muçulmanos, mulher negra por homem negro? Ou esses grupos náo tem nada em comum exceto a experiência comum de serem excluídos?" 7

Essas questôes permitem múltiplas respostas e também dão a dimensão do problema em pauta. Poder-se-ia pensar que a condição de excluídos de diferentes grupos criaria uma comunidade de interesses, no entanto, não há nenhum caminho predeterminado para que isto aconteça. A questão é mais complexa e envolve interrogar como cada um dos sujeitos

\footnotetext{
6 "We have become sufficiently attuned to the politics of presence to distrust the notion that anyone can "stand in" for anyone else, and sufficiently alert to the coercive powers of homogeneity to want to reflect diversity”. PHILLIPS, Anne. Equality, Difference. Public Representation. In: BENHABIB, Seyla. Democracy and Difference. Princeton: Princeton Press, 1996. p. 146. (Todas as traduçóes neste artigo são minhas, para uso exclusivo neste trabalho).

7 "Can Asians be represented by Afro-Caribbean, Hindus by Muslims, black women by black men? Or do these groups have nothing more in common than their joint experience of being excluded from power?” Ibid, p. 148.
} 
excluídos-incluídos pode se reconhecer nos outros. Ou, colocando o problema de outra forma, por que esses sujeitos se reconheceriam mutuamente? Não haveria inclusive a tendência de haver uma competição por espaço entre eles? Qualquer resposta a essas perguntas anterior ao cenário onde esses sujeitos estão colocados envolve uma posição essencialista pouco defensável. Mesmo quando as feministas atribuem mulheres, em princípio, com interesses iguais, como a luta contra a violência ou o direito a decidir sobre os seus próprios corpos, estão caindo em uma armadilha essencialista, que é bastante perniciosa para análise científica de contextos de opressão.

Mulheres e homens negros podem lutar juntos contra o racismo que atingem os dois, entretanto, este racismo está perpassado pelas relaçôes de gênero, facilmente verificáveis, no caso do Brasil, no assassinato de jovens negros do sexo masculino, nas constantes abordagens que estes sofrem de policiais, ou em uma atribuída sexualidade das mulheres negras. Também esses homens e mulheres negros podem pertencer a diferentes classes sociais e terem diferentes filiações religiosas e políticas. Portanto, a atribuição de identidade automática a essas pessoas constitui um grave erro analítico.

Para que se possa avançar nesta discussão não caindo em suas usuais armadilhas reducionistas-essencialistas, deve-se levar em consideração duas premissas: uma é a da complexidade das pessoas humanas na constituição de suas identidades, outra da complexidade da estrutura social. É na confluência desses processos que o binômio ideia/presença deve ser recolocado. A discussão trazida por Judith Butler acrescenta questôes importantes:

Seria errado supor de antemão a existência de uma categoria de "mulheres" que apenas necessitasse ser preenchida com os vários componentes de raça, classe, idade, etnia e sexualidade para tornar-se completa. A hipótese de sua incompletude essencial permite à categoria servir permanentemente como espaço disponível para os significados contestados. A incompletude por definição dessa categoria poderá, assim, vir a servir como um ideal normativo, livre de qualquer força coercitiva. ${ }^{8}$

Em um documentário sobre a vida Butler interroga-se:

Eu sou lésbica, gay. Mas eu aceito tudo que os movimentos lésbico e gay dizem? Eu sempre apareço primeiro como uma pessoa lésbica e uma gay? Eu sou uma gay primeiro? Antes de ser mulher, ser judia, ser americana, ser cidadá, ser filósofa? Não! Não é só uma identidade, estas são comunidades que um pertence ou um não pertence, e eu viajo de uma a outra. ${ }^{9}$

\footnotetext{
${ }^{8}$ BUTLER, Judith. Problemas de gênero: Feminismo e subversão de identidades. Rio de Janeiro: Civilização Brasileira, 2012. p. 36.

9 "Je suis lesbienne, Je suis gay, oui. Dois je pour autant adhéres à tout ce que dit le mouvement gay ? Est-ce que je me definir l'abord em tant que lesbienne ? Disons avant d'être femme ou juive, ou américaine, ou citoyenne, ou philosophe ? Ce n'est pas la seule identité vous savez. Appartenes ou non a telle ou telle vouz
} 
A descrição que Butler faz de si mesma é ilustrativa para o tema que se está introduzindo neste artigo. Pode-se parafrasear Butler em duas situaçôes distintas: 1. Eu sou mulher. Mas eu aceito tudo que o discurso contemporâneo diz sobre a mulher? Eu sempre apareço em primeiro lugar como mulher? 2. Eu sou feminista, mas eu aceito tudo que o movimento feminista diz? Eu sempre apareço primeiro como uma pessoa feminista?

As escolhas das pessoas humanas não ocorrem em um mundo de opções intermináveis, mas na relação das pessoas com a estrutura social que se não as determinam, as condicionam a um leque específico de possibilidades. Iris Young define estrutura social de uma forma que permite que se entenda o espaço da pessoa humana na ação:

Estruturas denotam a confluência de regras institucionais e rotinas interativas, mobilização de recursos e estruturas físicas que constituem as condiçōes historicamente dadas em relação às quais são relativamente estáveis no tempo. Estruturas também conotam uma larga soma de resultados que são efeitos da confluência de muitas ações individuais dentro de dadas relaçôes institucionais cujas consequências coletivas frequentemente não têm a marca de nenhuma pessoa individual. ${ }^{10}$

Tomando em consideração a estrutura, Young define três possibilidades de representação que dão pistas importantes para examinar a vida de um parlamentar e principalmente de uma parlamentar. Young afirma que se pode representar interesses, opinióes ou perspectiva:

Representar interesses ou opiniōes usualmente envolve promover certos resultados específicos no processo de tomada de decisão. Representar a perspectiva, de outra forma, usualmente significa promover certos pontos iniciais para a discussáo. De uma perspectiva social particular o representante faz alguns tipos de questóes, reporta certo tipo de experiência, relembra uma linha particular de narrativa histórica, ou expressa uma certa forma de ver a posição dos outros. ${ }^{11}$

savez. Moi, Je Voyage de une à l'autre" (Philosophe en tout genre). Disponível em: <http://www.youtube. com/watch?v=Q50nQUGiI3s>. Acesso em: $10 \mathrm{dez} .2012$.

10 "Structures denote the confluence of institutional rules and interactive routines, mobilization of resources, and physically structures, which constitute the historical givens in relation to which are relatively stable over time. Structures also connote the wider social outcomes that result from the confluence of many individuals actions within given institutional relations, whose collective consequences often do not bear the mark of any person or group's intention." YOUNG, Iris. On Female Body Experience. Oxford: Oxford University Press, 2005. p. 20.

11 "Representing an interest or an opinion usually entails promoting certain specific outcomes in the decision-making process. Representing a perspective, on the other hand, usually means promoting certain starting-points for discussion. From a particular social perspective a representative asks certain kinds of questions, reports certain hinds of experience, recalls a particular narrative history, or express a certain way of regarding the positions of other." YOUNG, Iris. Inclusion and Democracy. Oxford: Oxford University Press, 2000. p. 140. 
A ação humana, portanto, ocorre no interior da estrutura social que define a gama de possibilidades da própria ação, mas não se esgota aí: as próprias regras do campo não independente do indivíduo e da estrutura, mas com espaços consideráveis de poder, podem influenciar e desenhar posições onde se desenvolve a ação. Sem assumir aqui as problemáticas restriçôes do campo postas pela teoria de Bourdieu, ${ }^{12}$ pode-se assumir, entretanto, que existem campos ou espaços de possibilidades, como o político, que explicitam suas regras de forma tal que a sobrevivência em seu interior como jogador legítimo exige um redimensionamento da própria ação, possibilitada pela condição da incompletude do sujeito posto por Butler. Uma mulher chegando a um parlamento majoritariamente masculino pode, em uma sociedade tradicional, sexista, sem tradição de luta feminista, retrair a sua condição de mulher para melhor sobreviver no campo. Mas esta mesma mulher, se em uma condição específica tiver o apoio de uma categoria de trabalhadores do sexo feminino ou de um movimento feminista, poderá agir como um ponto avançado na ideia dos direitos das mulheres. Young defende que mulheres, negros, imigrantes e outras minorias são mais convenientemente representados a partir de uma perspectiva, ou seja, as mulheres podem representar interesses muito diversos, inclusive não feministas, podem ter opinióes muito diversas, ou seja, podem representar ideologias diversas, mas por sua condição de mulher terão sempre uma perspectiva diferente da do homem. Desta forma parece que Young resolve dois dilemas, o da presença/ideia e o da identidade posto por Butler. O primeiro refere-se à importância da presença, mesmo não acompanhada da ideia, porque sempre há uma perspectiva presente. $\mathrm{O}$ segundo dilema é o da identidade trazido por Butler, independentemente de se identificar como mulher, as mulheres no espaço público em 1950, por exemplo, encontravam limites por sua condição feminina, que necessitavam dar conta e não podiam fazer isso senão a partir de uma perspectiva feminina. Isso permite examinar a atuação de uma deputada como Suely de Oliveira sem entrar na discussão extemporânea se ela defendia ou não as mulheres ou se era bom ou não para as mulheres da década de 1950 no Rio Grande do Sul sua presença.

Trabalhar com a história das mulheres no campo da política permite uma combinação metodologicamente importante entre o que se chama de história da mulher e história de gênero. História das mulheres e história de gênero não são duas noçôes fáceis. A substituição da primeira pela segunda foi uma escolha importante em certo momento da teoria feminista e dos estudos sobre as mulheres, mas algumas vezes não avançou além de uma nova terminologia. Gostaria aqui de retomar as duas noçôes e limpar meu texto de algumas posições que me parecem equivocadas. Primeiro, a de que não se pode fazer a história das mulheres. Sim, se pode fazer a história das mulheres, como se pode fazer a história dos operários, dos cam-

\footnotetext{
${ }^{12}$ Bourdieu, em sua clássica teoria dos campos, desenvolve um esquema analítico rígido que não encontra correspondência muito além das situaçóes que analisa em suas obras, principalmente em La Distinction e em La Noblesse D'État. O sentido que estou dando a campo divide com Bourdieu apenas a noção de espaço delimitado por regras conhecidas por todos os jogadores. BOURDIEU, Pierre. La Distinction. Paris: Les Éditions de Minuit, 1979. BOURDIEU, Pierre. La Noblesse d'État. Paris: Les Editions de Minuit, 1989.
} 
poneses e de muitos outros sujeitos sociais. Entretanto, qualquer uma dessas histórias está atravessada por um conjunto de relaçóes de poder, que atuam com mais ou menos presença em relação a diferentes sujeitos e diferentes contextos. As relaçôes de gênero constituem uma dessas relações e a história das mulheres não pode ser escrita sem tomá-las em consideração. Isto posto, outra questão fica ainda em aberto: é a ideia de que, para incorporar as relaçóes de gênero, tenha-se de fazer concomitantemente à história das mulheres a história dos homens. Este é um entendimento muito rápido do que Joan Scott entendeu por gênero e que foi vastamente popularizado. Toda a vez que a história considera mulheres e homens como atuando no mundo privado ou público em uma estrutura pautada pelas relaçôes de gênero, se está usando na sua complexidade o conceito de relaçôes de gênero, não interessando se os personagens são mulheres ou homens. Butler, introduzindo uma obra coletiva sobre Joan Scott, expóe com muita fineza os problemas que o conceito de gênero trouxe e os cuidados que se deve ter com ele:

Eu destaco isto [o conceito de relaçóes de gênero] desde que provavelmente deve ser dito, especialmente dentro do contexto de um volume chamado $A$ questão de gênero em que ambas, Joan e eu, temos nos encontrado em momentos semiprivados dizendo "já o suficiente com gênero". (...), gênero é tomado como dado como ponto e partida para um conjunto de descriçôes de práticas sociais, entendidas como adjetivos que qualificam objetos estabelecidos da ciência social: gênero no trabalho, performance de gênero; jogo de gênero De fato, existe pouca investigação na produção da diferença e pouco investigaçẫo de como a diferença trabalha na produção de outras formas de categoria. ${ }^{13}$

No texto que se segue, a trajetória política de Suely de Oliveira será pontuada tomando em consideração as questôes concernentes à presença das mulheres na vida política e as formas que elas foram engendradas pelas especificidades das relaçóes de gênero, que perpassam as experiências de mulheres na política, como a de Suely de Oliveira.

13 "I point this out since it probably should be said, especially within the context of a volume called 'The Question of Gender', that both Joan and I have found ourselves in semi-private moments saying "enough already with gender"(...). Gender is taken for granted as the point of departure for a set of descriptions of social practices, understood as an adjective that qualifies established objects of social science: gendered work, gendered performance, gendered play. In fact, there is little inquiry on the production of difference, and little inquiry on how difference works in the production of other kinds of categories." BUTLER, Judith; WEED, Elizabeth (Ed.). Question of gender. Bloomington: Indiana University Press, 2011. p. 21. 


\section{Suely de Oliveira — uma pioneira}

Em 1937 Suely de Oliveira foi nomeada professora primária na cidade de Pelotas, no Rio Grande do Sul. ${ }^{14}$ Esta era uma das raras profissôes para mulheres à época, mas, mesmo assim, não era uma empreitada simples, pois exigia um curso de formaçấo feito em Porto Alegre e a aceitação de designação para uma cidade diferente da de origem. No caso de Suely era sua segunda mudança, pois, nascida em Osório, tinha se mudado para Porto Alegre para fazer seus estudos e daí para Pelotas. Este era um tempo em que jovens mulheres, solteiras na sua imensa maioria, circulavam sozinhas pelo interior do estado, respeitadas pelas famílias e pelas autoridades locais por seu saber. Circulavam no mundo público, com uma atividade revestida de importância, eram mulheres que haviam vivido na capital do estado e que tinham experiência de vida.

Era o primeiro ano do Estado Novo, o Brasil vivia um conturbado momento político e Suely de Oliveira passou todo o período da ditadura dando aulas em Pelotas. Sobre essa época se tem poucas informaçóes, mas em 1946 fazia parte do "movimento queremista" e constava como fundadora do PTB local, tendo sido eleita vereadora por Pelotas na primeira eleiçáo pós-ditadura em 1947. Após dois anos renunciou para assumir uma cadeira como deputada estadual eleita em 1950, posição que ocupou até 1974, por seis legislaturas. Este pequeno pedaço de biografia deixa uma primeira instigante questão: por que Suely se aproximou da vida política? O que diferenciava Suely das demais professoras que circulavam pelo estado? Não seria de se esperar que desse grupo de mulheres frequentando o espaço público aparecessem mais mulheres direcionadas para a política? Por que Suely foi a única a se lançar na política estadual? Há um dado importante em sua biografia que oferece pista sobre esta trajetória. Antes de ser nomeada professora, Suely trabalhou na Viação Férrea do Rio Grande do Sul, este foi o seu primeiro emprego. E lá conheceu Wolfran Abreu de Oliveira Filho, advogado com quem se casou nos anos 1940. Em 1945 Wolfran Oliveira se candidatou a deputado federal pelo PTB, perdendo as eleiçōes e fazendo apenas 521 votos..$^{15}$ Posteriormente tornou-se promotor público, nunca mais se envolvendo com política. Portanto, possivelmente a entrada de Suely na política aconteceu através do marido, que primeiro se tornou candidato a um cargo eletivo, o que náo explica, todavia, sua excepcional trajetória de 24 anos no legislativo estadual: estamos frente a uma personagem muito particular. Consta do depoimento de um deputado colega seu à época que a deputada dizia que tinha entrado na política a convite de Getúlio Vargas. ${ }^{16}$

\footnotetext{
${ }^{14} \mathrm{O}$ curso primário referia-se aos cinco anos de educação formal, após os quais os alunos faziam exame de admissão ao ginásio. As professoras primárias faziam o Curso Normal, que correspondia ao atual ensino médio. 15 Eleições pós-1945. Disponível em: <http://www.eleicoespos1945.com/19451965/ rio_grande_do_ sul_1945_federais_ptb.html>. Acesso em: 7 jan. 2013.

16 "A deputada Suely contava que havia sido o Dr. Getúlio Vargas, em 1950, durante a sua campanha para presidente da República, quem havia determinado que ela fosse candidata a deputada, por ocasião de uma
} 
A presença de Suely de Oliveira causava estranheza naquele ambiente eminentemente masculino. Daí que as questôes a serem investigadas relacionam-se a tal fato: Que tipo de estranhamento causava? Como a deputada se organizava e se comportava neste cenário? Que diferença fez para a Assembleia Legislativa e para as mulheres no Rio Grande do Sul ter Suely de Oliveira por 24 anos no plenário, sendo que 16 deles como a única mulher? A biografia institucional de Suely de Oliveira está em uma coleção de perfis biográficos realizados pela Superintendência de Comunicação Social da Assembleia Legislativa. O volume referente à deputada data de 2007. O texto introdutório do volume tem como título "Perfil de uma pioneira":

Apesar de toda a sua liderança, jamais abriu mão da simplicidade. Só em grandes eventos políticos comparecia maquiada e, ainda assim, de forma discreta. Não tinha empregada doméstica, apenas uma amiga que duas vezes por semana limpava seu apartamento na Riachuelo, bem próximo à Assembleia. À noite, a deputada preparava pessoalmente a refeição para o dia seguinte e esporadicamente almoçava fora com o marido, assim mesmo só em fins de semana. Ela própria cuidava das roupas do casal e, a quem estranhasse seus hábitos, justificava: "O fato de ser deputada não me tira a condição prioritária de dona de casa". ${ }^{17}$

Já no século XXI, o biógrafo oficial ressalta como qualidade da deputada a liderança, mas uma liderança que não apagava as qualidades da mulher tradicional: não usava maquiagem; preparava as próprias refeiçóes; lavava a roupa do marido, era pois antes de tudo uma "dona de casa". Tal caracterização é muito importante não tanto pelo que nos conta da biografia de Suely, mas pelo que fala dos valores da instituição - Assembleia Legislativa do Estado - do espaço masculino, onde a mulher deveria ser humilde e antes de tudo dona de casa.

Mas Suely fumava e tomava muito café, isso também aparece na biografia. Esses hábitos não são detalhes, pois estavam na época associados ao mundo masculino ou a mulheres "emancipadas". As casas de cafés das cidades brasileiras eram redutos masculinos e mulheres não entravam ali, pelo menos sozinhas. Interessante observar que na década de 1950 houve a presença de publicidade de cigarros direcionada para mulheres, que associava o hábito de fumar a independência e modernidade. Portanto, não se deve tão facilmente aceitar esta figura estereotipada de mulher dona de casa atribuída a Suely. ${ }^{18}$

visita dele a Pelotas. Ela trabalhava como professora e era líder política naquele município. Não tenho certeza de que já era vereadora, mas sei que fazia e acontecia lá.” Depoimento de Sybilla Ribeiro. In: Divisão de Biblioteca e Memória Parlamentar (Coord.). Perfis parlamentares (v. 11) Suely de Oliveira. Perfil Biográfico. Depoimentos e discursos. Porto Alegre: Assembleia Legislativa do Rio Grande do Sul, 2007. p. 56.

${ }^{17}$ TERLERA, João Carlos. Perfil de uma pioneira, op. cit. p. 25.

${ }^{18}$ Silvia Sasaki analisando os comerciais de cigarro em revistas femininas entre 1940 e 1950 afirma: "Ainda em 1948, os cigarros Hollywood publicam outra peça, com características mais femininas que esta anteriormente apresentada. Trata-se da ilustração de uma sequência como se estivesse registrada no negativo de um 
No perfil biográfico da deputada constam depoimentos de deputados seus contemporâneos e que foram dados mais de 30 anos após esta convivência. Alguns deles revelam o quanto está enraizado de uma perspectiva masculina em relação à forma como mulheres devem se comportar no espaço público. O primeiro desses depoimentos é do deputado Alberto Hoffmann: $:^{19}$

A deputada Suely se relacionava bem com todos os parlamentares, era respeitada pelos adversários e pelos companheiros. Foi inédito para nós, 54 homens, termos uma mulher no nosso meio, mas é preciso registrar que ela tinha muita linha, muita discrição e recato, sabia se fazer entender e dialogar conosco. ${ }^{20}$

O depoimento do deputado Hoffman é paradigmático da forma como uma mulher era vista e tolerada no mundo público. O deputado fala do estranhamento que a presença da deputada causava e explicitamente acrescenta um "mas" na sua declaração, e isto não é um detalhe, pois se tratava de uma mulher no lugar errado, mas que "tinha muita linha" "discrição e recato". O Dicionário Aurélio afirma que "andar na linha", "manter a linha" significa correção na maneira e no procedimento; já para "recato" o dicionário associa cautela; prudência; resguardo; modéstia; simplicidade; pudor. ${ }^{21}$ Nenhum destes adjetivos é associado à vida pública ou política, mas à vida privada da mulher "honesta". Este depoimento permite verificar a força da estrutura na ação humana, pois o deputado está falando mais de 30 anos depois da saída de cena de Suely, após toda a onda do movimento feminista, mas usa expressóes e julgamentos morais de 1950. Isto é uma pista muito vigorosa para se entender as dificuldades que até hoje as mulheres têm para chegar ao parlamento.

O depoimento do deputado Aluísio Paraguassu ${ }^{22}$ divide com o primeiro a ideia do bom comportamento: "sobriamente vestida" com uma "vida política exemplar". Mas avança em dois aspectos, faz elogios à elegância e à inteligência, mas também reconhece as dificuldades que ela teve por ser a única mulher, dificuldades essas que qualifica como natural.

filme, que demonstra uma mulher fumando o cigarro da devida marca. O foco está em seu rosto, e o olhar da personagem encontra-se desviado para cima. Um sorriso deixa transparecer o prazer que ela está sentindo pelo uso do cigarro. O filtro está marcado pelo batom utilizado pela personagem.” SASAK, Silvia. Smoking fetish: representaçôes femininas nas Propagandas de cigarro (1940-1960). Fazendo Gênero 9. Diásporas, Diversidades, Deslocamentos. 23-26 ago. 2010. Disponível em: <www.fazendogenero.ufsc.br/9/resources/ anais/1277920551_ARQUIVO_SmokingFetish_SilviaSasaki>. Acesso em: 13 dez. 2012.

${ }^{19}$ Alberto Hoffemann nasceu em 1920, em Ijuí, RS. Foi deputado estadual por três legislaturas e federal por cinco. Militou no PRP, na Arena, no PDS e no PP.

${ }^{20}$ HOFFMANN, Alberto. Depoimento. In: Divisão de Biblioteca e Memória Parlamentar (Coord.). Perfis parlamentares (v. 11) Suely de Oliveira. Perfil Biográfico. Depoimentos e discursos. Porto Alegre: Assembleia Legislativa do Rio Grande do Sul, 2007. p. 37.

${ }^{21}$ FERREIRA, Aurelio Buarque de Holanda. Novo Dicionário Eletrônico Aurélio versão 7.0. São Paulo: Positivo, 2011.

${ }^{22}$ Aluisio Paraguassu foi deputado estadual por duas legislaturas e federal por uma. Militou no MDB e PMDB. 
Normalmente usava o cabelo curtinho, escuro, sempre sobriamente trajada, muito elegante, e desenvolvia uma vida política exemplar... É certo que um mandato tem muitos envolvimentos, e ela, além de enfrentar as dificuldades naturais, sendo a primeira e única mulher na época, tinha que ser ainda melhor do que os outros - e sei que todas as deputadas continuam procurando agir assim. Não lembro de ela ter sofrido algum tipo de discriminação por ser mulher, já que foi aceita em consequência de sua competência e conhecimento. ${ }^{23}$

O deputado aponta para "dificuldades naturais", ou seja, a dificuldade de uma única mulher em meio aos homens, e faz uma afirmação importante: ela tinha de ser a melhor porque era mulher. Já o deputado Lauro Hagmann teve uma percepção distinta:

Não exagerando, devo dizer que, naquela época, havia uma certa discriminação em relação à deputada Suely. Minha formação política não permitia isso, e para mim tratava-se de uma parlamentar igual aos demais. Mas sentíamos que havia no ar uma restrição ao fato de ela ser dirigente de uma categoria na condição de mulher. Não havia outra pessoa que pudesse exercer essa representação relativamente àquela categoria. Tudo isso se reconhecia, mas devo dizer que havia um laivo machista no fundo de certos episódios, o qual não se verificava de forma visível, mas sempre havia este componente. Ela se impunha como mulher e como dirigente classista. O restante dos parlamentares tinha que baixar a crista, gerando uma situação não bem aceita. Isso tudo era subjacente, não posso citar um episódio em que isso tenha ficado claro. Ninguém se atreveria a agir às claras neste sentido. ${ }^{24}$

Hagmann era um deputado comunista eleito pelo mesmo partido de Suely, o PTB, e mostra-se bastante distinto em relação a seus colegas, não via como natural as dificuldades de Suely, mas como preconceito do partido, que não deixou que ela ascendesse na carreira porque era um partido machista, este é o termo que ele usa. Aqui fica explícita a tensão que existia na disputa de poder dentro do partido, quando ela vencia pela força que possuía como representante dos professores e funcionários públicos. Pelo depoimento de Hagmann percebe-se que a presença de Suely abalava o cenário da Assembleia, criando tensóes nitidamente decorrentes das relaçóes de gênero. Já o deputado Ney Borges segue o mesmo padrão dos depoimentos anteriores:

A Suely era uma mulher muito vistosa, muito bonita, muito elegante, uma lutadora, que brigava com qualquer um em benefício da sua classe, o magistério. Chamava muito a atenção, exatamente porque naquela época não existia nenhuma mulher deputada. Não me lembro

\footnotetext{
${ }^{23}$ PARAGUASSU, Aluisio. Depoimento. In: Divisão de Biblioteca e Memória Parlamentar (Coord.). Perfis parlamentares (v. 11) Suely de Oliveira. Perfil Biográfico. Depoimentos e discursos. Porto Alegre: Assembleia Legislativa do Rio Grande do Sul, 2007. p. 39.

${ }^{24}$ HAGMANN, Lauro. Depoimento, op. cit., p. 47.
} 
de haver outras candidatas, a não ser ela. Foi a primeira deputada, e isso a destacava não somente porque era aguerrida, lutadora, trabalhadora, mas exatamente por ser uma pessoa do sexo feminino no meio de homens, enfrentando todos os parlamentares que se opunham aos seus argumentos. Lembro-me de que todos a admiravam por sua luta, seu trabalho e sua inteligência. ${ }^{25}$

A primeira característica a que o deputado refere-se são as qualidades físicas da deputada: vistosa, bonita e elegante, para depois falar de suas qualidades como política. Também como Paraguassu, aponta suas dificuldades por ser mulher, mas diferentemente de Hagmann, não via tensão, mas admiração. É mister observar como a perspectiva masculina tende a homogeneizar os depoimentos dos deputados. Ney Borges, por exemplo, era um deputado da esquerda do PTB, tendo sido cassado pelo AI-1 de 10 de abril de 1964, mas em relação a Suely tem posição muito próxima de Hoffeman, que foi militante do PRP, um dos partidos mais à direita do espectro político brasileiro.

Um depoimento especialmente importante sobre Suely é o da deputada Terezinha Irigaray, pois ela é a segunda mulher a chegar à Assembleia Legislativa, eleita em 1966. Irigaray havia sido mulher do prefeito cassado de Porto Alegre Sereno Chaise; ela mesmo dizia que havia sido eleita pelos eleitores dos cassados. Dois anos depois, ela própria foi cassada. Mas aqui seu depoimento é significativo, não pelo que ela representou politicamente, mas pela relação que estabeleceu com Suely de Oliveira. Terezinha tem uma visão muito clara do que era ser mulher naquela época nos partidos políticos:

Naquela época, a presença feminina não era bem recebida dentro dos partidos políticos, pois as mulheres não faziam o seu caminho natural dentro da política. Elas não se introduziam em partidos políticos. Até afirmo que eram malvistas quando entravam para um partido político, porque se tratava de um núcleo onde o elemento formador era quase exclusivamente de homens. A presença do elemento feminino nos partidos políticos causava descaso. Os homens não davam muita confiança, olhavam meio de lado, nem acreditavam muito no que a gente dizia. ${ }^{26}$

$\mathrm{Na}$ continuidade de seu depoimento, expressa mais explicitamente o preconceito que sofriam:

Juntas, procurávamos estabelecer um ambiente de harmonia e afastar um pouco a grande diferença que havia entre os homens e as mulheres, tanto fora da Casa quanto dentro. Lembrome de ter sido barrada, muitas vezes, na entrada de reunióes de comissões, na apresentação de projetos, e a deputada Suely de Oliveira também. Em determinada época, a deputada foi

\footnotetext{
${ }^{25}$ BORGES, Ney. Depoimento, op. cit., p. 49.

${ }^{26}$ IRIGARAY, Terezinha. Depoimento, op. cit., p. 58. 
presidente da Comissão de Serviço Público, consequentemente, tinha autoridade. Aí, então, eu tinha a oportunidade de falar. ${ }^{27}$

Terezinha Irigaray descreve um ambiente que nem os depoimentos dos deputados nem as manifestaçôes de Suely no plenário deixam transparecer, ou seja, um ambiente onde elas eram barradas e que ela, como nova deputada, só conseguia falar porque na Comissão do Serviço Público havia uma mulher como presidente. Isso vem ao encontro do depoimento de Hagmman, que a partir de uma postura ideológica percebia o preconceito contra Suely. No depoimento da deputada ela refere-se ao fato de ser muito jovem e de ter se aproximado de Suely, para pedir conselhos, nos encontros do cafezinho. E em um desses encontros ela relata um diálogo que é revelador da solidariedade de gênero que se criou:

Lembro-me de que, em determinado dia, quando estávamos tomando um cafezinho no prédio da antiga Assembleia, a deputada Suely me disse: Terezinha, toma atenção em certas coisas. Eu lhe perguntei no que deveria prestar a atençáo. Então me disse: Tu fizeste uma grande votação, menina - ela era um pouco mais velha do que eu. Eu lhe respondi: Sim, fiz 51.416 votos. Continuou: Essa é uma grande votaçẫo. Então, tu tens — e me disse rindo — que ser a nossa presidente... Tu vais ser a nossa presidente, porque o normal da Casa é eleger para a presidência, sempre, no princípio das legislaturas, o deputado que tiver feito a maior votação. ${ }^{28}$

Fica claro, na forma como Terezinha Irigaray relata a fala de Suely, que esta sabia, e por isso ironizava com um riso, que mesmo sendo a mais votada ela não seria a presidente, por ser mulher.

Tomando os depoimentos em seu conjunto, percebe-se que a presença de uma mulher na Assembleia Legislativa gaúcha transformava o cenário; os depoimentos são enfáticos em declarar que era diferente e que era estranho conviver com uma mulher. É difícil, entretanto, afirmar para quem pesou mais esta situação, se para os deputados homens ou para a deputada Suely.

Para os deputados parece claro, pelos depoimentos, que antes de qualquer característica que pudesse ser a ela atribuída, vinha o fato de ser mulher. Eles estavam se relacionando antes de tudo com uma mulher e viam nela as qualidades que atribuíam ao sexo feminino. Isso certamente tem contrapartida no comportamento da deputada, a questáo é saber até onde ela própria se via como uma mulher deputada ou como uma deputada mulher. Trazendo Butler para a discussão, o que necessita ser investigado é até onde o fato de ser mulher determinava ou influenciava seu posicionamento no parlamento. Suely de Oliveira foi uma deputada que teve como preocupaçáo principal defender as professoras primárias e ao longo

\footnotetext{
${ }^{27}$ Ibid, p. 58.

${ }^{28}$ Ibid, p. 58. 
de seus mandatos o funcionalismo público em geral, ficando popular pela chamada "Lei Suely", que garantia um ano a menos de trabalho para se chegar a aposentadoria a cada seis anos de trabalho sem faltas não justificadas. Segundo Terlera:

Ao todo, apresentou 26 projetos concedendo vantagens ao magistério, dos quais 25 foram convertidos em lei. Também foi autora de outros 20 projetos beneficiando o funcionalismo, dos quais 16 foram convertidos em lei. (...). Dentre seus projetos, os mais destacados foram o da aposentadoria dos professores aos 25 anos de efetivo exercício do cargo em sala de aula, o que possibilitou a aposentadoria de milhares de integrantes dos quadros do magistério.

Outra lei de sua autoria, também de grande repercussão, beneficiou os demais servidores públicos. Conhecida como "Lei Suely". ${ }^{29}$

A dedicação de Suely de Oliveira à causa do funcionalismo lhe garantia ter por diversas vezes a Presidência da Comissão de Serviço Público. ${ }^{30}$ Ela foi a típica deputada que não defendia opinióes ou ideologias, mas defendia muito claramente interesses de um grupo muito definido - os funcionários públicos estaduais. Houve uma longa relação de fidelidade entre a deputada e o grupo. Talvez, na história do legislativo rio-grandense, à exceção dos deputados representantes do MST, não tenha havido nenhum deputado ou deputada tão completamente identificada com uma categoria. Suely militava no PTB, Partido Trabalhista Brasileiro, e esta filiação era muito coerente com sua luta pelos direitos trabalhistas. Entretanto, 1964 não criou grandes problemas para a deputada, que era vista como moderada, e manifestou-se de forma bastante contraditória em um pronunciamento ainda em abril de 1964. Primeiro declarou sua submissão:

Aprendi, Sr. Presidente, que, quando as Forças Armadas se unem para aniquilar o poder civil, toda a estrutura jurídica que o sustenta cai por terra e o que prevalece é a vontade dos vencedores e a força das armas. É por isto, Sr. Presidente, que, como vencida, só teria um caminho a seguir: sujeitar-me à imposição das armas vitoriosas acomodar-me no regime que me foi imposto pela força. ${ }^{31}$

Mas no parágrafo adiante afirmou:

\footnotetext{
${ }^{29}$ TERLERA, João Carlos. Perfil de uma pioneira, op. cit., p. 26.

30 "A liderança da bancada do PTB fez um acordo com outros partidos e cedeu ao Partido Social Democrático (PSD) a vaga na Comissão de Educação em troca de uma cadeira na de Serviço Público, destinada a Suely, que a ocupou a partir de dezembro de 1953, permanecendo na legislatura seguinte. Foi na sua segunda reeleição que galgou a Presidência da Comissão, em 1959, onde permaneceu até 1961, tendo retornado ao cargo em 1964 e lá permanecido sem interrupção até 1972. Foram 11 anos de presidência e dois como vice-presidente" (1962e 1963). Ibid, p. 24.

${ }^{31}$ OLIVEIRA, Suely. Discursos, op. cit., p. 101. Discurso pronunciado na $20^{\text {a }}$ sessão, em 14 de abril de 1964.
} 
Sr. Presidente e nobres colegas, não é mais possível calar, porque o silêncio, então, é covardia, náo sou covarde e, por isso, aqui estou para protestar com veemência, com toda a força da minha alma, contra as perseguiçóes que se estão desencadeando, em todo o território nacional pelos agentes da autoridade, que dizem falar em nome do Comando Revolucionário vitorioso. ${ }^{32}$

A deputada Suely de Oliveira militou dentro de uma Assembleia Legislativa dominada por homens, onde tirava sua força política na representação dos interesses dos funcionários públicos. Neste cenário cabe indagar sobre como Suely identificava-se como mulher. Dos pronunciamentos feitos pela deputada na Assembleia em quatro discursos, a questão da mulher parece com muita ênfase e de diferentes formas. ${ }^{33}$ Os indicativos são de que Suely defendeu as mulheres no parlamento, porque as professoras primárias eram mulheres, e não ao contrário, defendeu as professoras primárias porque eram mulheres. Poucas vezes ao longo de seu mandato falou do fato de ser mulher ou dos direitos das mulheres. Quando tomou posse pela primeira vez assim se manifestou:

A minha presença nesta Casa - a primeira mulher que nela toma assento em toda a história política do Rio Grande como parte do Legislativo — devo, sem dúvida, a aprovação do eleitorado gaúcho a um dos mais democráticos princípios da Constituiçâo - a igualdade de direitos políticos atribuída a ambos sexos. É desnecessário justificar as razóes desse dispositivo a que se opõem, atualmente, apenas os indivíduos manifestamente reacionários, cuja existência é preferível ignorar. Vem pois, nobres e ilustres representantes do povo, a mulher rio-grandense, por meu intermédio, trazer-lhes a sua cooperação, o seu civismo, o seu entusiasmo e a sua dedicação à solução dos problemas sociais, econômicos e políticos do Rio Grande. ${ }^{34}$

Neste pronunciamento inaugural chama a atenção como Suely minimizou o preconceito contra a mulher, atribuindo-o a "indivíduos manifestamente reacionários". Este discurso foi feito em 1951, quatro anos após a Constituição que redemocratizou o país, em pleno período pós-guerra. Este era um momento de reconstrução da democracia no mundo. $\mathrm{O}$ termo "reacionário" pontua esta situação, sendo associado como aquele que não aceita direitos iguais. Não se tratava, pois, de apontar conservadores ou sexistas. Após uma onda totalitária que havia varrido o mundo e o próprio Estado Novo no Brasil, a percepçáo que a democracia restaurada garantiria a igualdade era muito forte, e a percepçáo de Suely é que a Constituição por si só garantiria direitos iguais para todos, inclusive para as mulheres. Suely, portanto, não se coloca como diferente por ser mulher, não é esta identidade que lhe diferenciará. Anotou apenas o fato excepcional de ser a primeira mulher a entrar no parlamento gaúcho.

\footnotetext{
${ }^{32}$ Ibid.

${ }^{33}$ Os pronunciamentos escolhidos não serão analisados a partir da ordem cronológica, mas a partir de temas. ${ }^{34}$ OLIVEIRA, Suely. Discursos, op. cit., p. 63. Discurso pronunciado na 2a sessão, em 8 de fevereiro de 1951.
} 
A segunda manifestação de Suely sobre sua condição de mulher é até hilária, pois trata-se de um "bate-boca" com o deputado Peracchi Barcellos, um militar da Brigada Militar que veio a ser posteriormente governador do estado indicado pelo governo militar:

A SRA. SUELY DE OLIVEIRA - Vamos discutir o problema com calma. Sempre dizem que eu é que me altero e que sou nervosa. Sempre estão dizendo que as mulheres é que não se entendem, mas aqui são os homens que náo se entendem.

O Sr. Peracchi Barcellos - O mais difícil é as mulheres se entenderem. Os homens se entendem sempre, apesar da exaltação. As mulheres não se entendem nunca.

A SRA. SUELY DE OLIVEIRA - Em parte concordo com V. Exa. Os homens, às vezes, se entendem. Se as mulheres tomassem mais interesse pela política, muita coisa que anda por aí não teria acontecido. ${ }^{35}$

A manifestação de Suely deixou claro o ambiente em que vivia na Assembleia Legislativa, pois afirmou que, sempre que se alterava, a chamavam de nervosa, e ela própria associou isso à acusação de que as mulheres não se entendiam. É possível inferir destas palavras que Suely era chamada de nervosa porque era mulher. Peracchi, que era também seu adversário político, reforça o preconceito e a resposta e Suely insinua que por trás do entendimento elogiado pelo deputado havia acordos não recomendáveis. Ainda em relação ao fragmento acima vale chamar a atençáo para o fato de que Suely lamentava que as mulheres não se interessassem por política, pois acreditava que tudo seria diferente, caso isso acontecesse.

A terceira intervenção de Suely referindo-se especificamente a mulheres é a mais significativa. Trata-se de um longo discurso defendendo as professoras mães e estudantes. O peculiar é que a deputada luta contra a posição de outra mulher, a superintendente do Ensino Primário do estado:

Permito-me crer, porém, que a razão de tão incongruente pronunciamento outra não é senão a de desprestigiar o Magistério na hora presente, abatendo-lhe a moral, para enfraquecê-lo na luta pela reivindicaçáo de melhores vencimentos. Não logrará entretanto, o seu intento. $\mathrm{O}$ Magistério tem consciência do valor do seu trabalho, da dedicaçâo com que o exerce e não se deixará embair com tão solerte trama. A professora casada, embora mãe, cuida, como as solteiras, com desvelo, suas obrigações de educadora, o mesmo acontecendo com as professoras estudantes. $\mathrm{O}$ fato de serem casadas ou estudantes náo as incompatibiliza para o exercício do magistério. O que realmente lhes dificulta esse exercício são as preocupaçóes decorrentes dos baixos vencimentos, preocupaçôes com que também lutam as professoras solteiras. ${ }^{36}$

\footnotetext{
${ }^{35}$ Ibid, p. 81. Discurso pronunciado na $18^{\text {a }}$ sessão, em 16 de maio de 1952.

${ }^{36}$ Ibid, p. 144. Discurso pronunciado na 44a sessão, em 26 de junho de 1956. 
Suely, em sua defesa da mulher casada ou estudante, associa os problemas das professoras não a seu estado civil, ou ao fato de terem ou não filhos, mas às dificuldades salariais, grande luta de seus sucessivos mandatos. Em meados da década de 1950 parece estar definido que a mulher deveria trabalhar até casar, porque depois seu papel de mãe lhe tomaria toda atenção, impedindo-a de ser profissional. É interessante como aqui ter filho não agrega experiência com crianças, o que seria uma qualidade das mães, mas retira o "desvelo". Na continuação do pronunciamento a deputada envolve as questôes de celibato e do aborto:

Ao investir contra o Magistério não deixou a Exma. Sra. Superintendente do Ensino Primário de aguilhoar também esta Assembleia Legislativa, acusando-a de ter elaborado "uma Lei unilateral" cujas disposiçōes dão margem a que as professoras casadas e gestantes se tornem "simplesmente pensionistas do Estado que geram novos pensionistas", pelo que é de se concluir que, no seu entender, o celibato deve ser instituído para o Magistério, ou então se deva consagrar o aborto como instituiçâo capaz de restabelecer o ensino conturbado pelo amparo que a legislação instituiu para a maternidade, para as professoras casadas e para as professoras estudantes. ${ }^{37}$

$\mathrm{Na}$ defesa das professoras casadas, Suely acusou a superintendente do Ensino Primário de obrigar a mulher ao celibato ou ao aborto. Tal postura merece ser cuidadosamente entendida, pois não pressupóe ideais avançados ou subversivos que um historiador da segunda década do século XXI pode erroneamente interpretar, devido ao tabu que se tornou o tema do aborto na política brasileira nas primeiras décadas do século XXI. Este pronunciamento foi feito em 1956, época em que se esperava que as mulheres casassem virgens e que ocupassem de preferência um lugar como dona de casa e mãe. Até 1962, quando foi promulgado o Estatuto da Mulher Casada, ${ }^{38}$ as mulheres brasileiras, quando casavam, praticamente perdiam sua condiçấo de cidadã. Nesta época, não havia movimento feminista nem campanhas a favor da legalização do aborto, mas parece que o abortamento não era um problema moral. Os métodos contraceptivos ainda eram muito precários e a interrupçáo provocada da gravidez era uma alternativa possível. É, portanto, neste cenário que Suely fala abertamente da possibilidade do aborto, não porque estivesse subvertendo a ordem, mas porque esta era uma forma de contraceptivo aventada sem muitos tabus por mulheres que engravidavam e não queriam ou não podiam ter filhos. Suely finaliza seu discurso defendendo as creches, uma luta das mulheres que ultrapassou em muito o tempo de vida da deputada, sendo até hoje motivo de disputa:

\footnotetext{
${ }^{37}$ Ibid, p. 146. Discurso pronunciado na 44a sessão, em 26 de junho de 1956.

${ }^{38}$ Estatuto da Mulher Casada - Lei n. ${ }^{0} 4.121$, de 27 de agosto de 1962. Antes da lei de 1962 a mulher casada era regida pelo Código Civil de 1916, que transformava a mulher casada em cidadã de segunda classe, não podendo trabalhar, fazer compras a crédito ou receber herança sem a permissão do marido.
} 
Por que, em vez de atacar o Magistério e um dos poderes do Governo, não propóe a Superintendência do Ensino Primário medidas capazes de sanar a desorganização que diz existir no setor educacional do Estado? Por que, já que se referiu às professoras casadas, não propóe a criação de creches, a exemplo da que existe no Instituto de Educação, para que os filhos das professoras não fiquem entregues aos cuidados de empregadas ou de vizinhos? É natural, é humano, que as professoras que deixam seus filhos em casa ou em casas alheias, sem nenhuma segurança, se mostrem intranquilas e preocupadas durante as horas de trabalho. Essa intranquilidade, essa preocupação, porém, não justificam sejam, por isso, taxadas de "elementos nocivos e até mesmo perniciosos ao Ensino"; antes, pelo contrário, mais as recomendam ao exercício das funções que exercem, pois é evidente que quem não se preocupa com os próprios filhos muito menos se preocupará com filhos de outrem. Quem não é boa mãe, não pode, de forma alguma, ser boa mestra. É lamentável que não pense assim a Sra. superintendente do Ensino Primário que, além de mulher é professora e, possivelmente, mãe. É, pois, de se repetir neste final, aplicando-se perfeitamente ao caso, a Palavra Divina: Perdoai, Ela não sabe o que faz. ${ }^{39}$

A defesa da mulher com filhos feita por Suely vem ao encontro de duas questóes discutidas pelas teóricas feministas anteriormente: a questão da presença de Phillips e da perspectiva de Young. A deputada foi uma defensora dos interesses dos funcionários públicos e principalmente das professoras. Era conhecida como a deputada dos funcionários e seus projetos de leis atestam isso. Mas era uma mulher representando as professoras, uma categoria quase na sua totalidade de mulheres, e quando defendeu as máes, dizendo que o que necessitavam era de mais salário e creches, estava presente uma perspectiva feminina, que dificilmente teria espaço de expressão sem a presença de uma mulher como deputada. Nisto transparece a complexidade da representação, pois ela transcende a própria intenção do sujeito. Ela decorre da relação do sujeito inserido em um cenário que implica a atualização constante das estruturas. E neste cenário a condição de gênero é dada pelas relaçóes definidas historicamente pela estrutura, antes de qualquer trabalho de constituição de identidade ou negação dela. Na década 1950 no Brasil, no estado do Rio Grande do Sul, ser mulher já tinha claras implicaçóes para a vida de uma pessoa. No caso de Suely tal determinação deve ser considerada em um cenário onde não era esperada a sua presença. $\mathrm{O}$ espaço para as mulheres, independentemente de classe social e mesmo do grau de instrução, era muito limitado e delimitado. A deputada, quando atravessou estes limites, mesmo que não o tenha feito a partir de uma militância feminista, o fez como mulher. Assim era vista e isso conformava a relação que tinha com o ambiente legislativo.

O quarto tema relacionado com a questão da mulher é o do menor abandonado e a melhor solução para a sua educação. Suely colocava-se completamente contra os lares provisó-

${ }^{39}$ OLIVEIRA, Suely. Discursos, op. cit., p. 147. Discurso pronunciado na 44a sessão, em 26 de junho de 1956. 
rios através de adoção, defendendo lares coletivos como a melhor forma de educação. Aqui é particularmente importante anotarmos a reação dos deputados. A discussão girou em torno de duas alternativas para resolver a questão do menor abandonado, asilos ou lares provisórios mediante pagamento das famílias para a adoção. Suely defendeu os asilos enquanto os deputados que se manifestam a acusavam de impedir que as crianças tivessem o que é "natural ter" um lar com pai e mãe. Suely argumentava:

Geralmente as crianças abandonadas, recolhidas a asilos ou instituições congêneres, são procuradas não para receber educaçấo e ter um lar, mas para prestar gratuitamente aos seus "benfeitores" toda a sorte de trabalho, principalmente, em se tratando de meninas, os trabalhos domésticos, mesmo os mais pesados. Essa é, de fato, a mentalidade que predomina naqueles que vão bater às portas dos asilos para dele retirar crianças indefesas. Só há uma solução para o problema. É a criaçẫo do maior número de lares coletivos sob a orientação e fiscalização de um órgão técnico e idôneo devidamente aparelhado; é o amparo sistemático e intensivo às instituiçóes já existentes desde que se submetam à orientação e fiscalização do Governo. Lares coletivos onde crianças abandonadas vivam e se desenvolvam num regime à base da saúde, da alegria e de uma atividade adequada e construtiva. ${ }^{40}$

Duas questôes chamam a atenção no fragmento acima, a primeira é a própria posição de uma mulher contra o princípio do lar e da família, o segundo é ter assinalado a posição das crianças do sexo feminino que se tornavam empregadas domésticas. Em um segundo pronunciamento sobre o mesmo tema, a deputada explicitou sua ideia:

Da desintegração da família, da sua incapacidade educacional e da ausência de princípios é que provém a maioria, a quase totalidade, das crianças abandonadas e necessitadas. Como, pois, pensarem recolher a um lar estranho aquele que náo encontrou no seu os socorros materiais e espirituais de que carece? Analisemos, com sinceridade, este aspecto do problema. A família moderna perdeu, há muito, na sua maioria, a velha feiçẫo clássica, em que as mães cuidavam exclusivamente dos lares e neles exerciam toda a sua atividade. As contingências da vida cotidiana, a instabilidade econômica, com que lutam as famílias da classe pobre e da classe média, levam os seus membros à dispersão quase permanente a que os obriga a necessidade do trabalho. ${ }^{41}$

A deputada, ao falar de desintegração da família, colocava-se completamente dentro do seu tempo. Ela responsabilizava as condiçóes econômicas, as dificuldades materiais, pela crise familiar, mas apontava a mãe como sujeito fundamental faltante nesta família devido 
às dificuldades econômicas. A deputada estava indicando o lugar da mulher na casa e a necessidade de sua saída para complementar à renda com a causa da desagregaçáo familiar.

Suely de Oliveira esteve 24 anos na Assembleia Legislativa, lá se destacou por ser uma defensora intransigente dos interesses do funcionalismo público, este era seu compromisso fundamental. Em um ambiente pouco afeito à presença de mulheres construiu, um nicho para o seu trabalho e se reelegeu muitas vezes graças a seus projetos beneficiando o funcionalismo e o magistério. Mas Suely foi uma exceção no parlamento gaúcho por ser mulher. Nunca defendeu as mulheres por serem mulheres; seu primeiro depoimento como deputada deixou claro que para ela esta era uma questão superada, mas não podia deixar de sentir-se mulher quando era chamada de nervosa. Até onde Suely de Oliveira achava que os limites que tinha na Assembleia eram da natureza de sua condição de mulher é uma questáo que não se pode responder. Em raros momentos foi possível ver a deputada mostrar que sabia o peso de sua condição de mulher. O diálogo com Terezinha Irigaray é importante neste aspecto. Em suma, o que interessa na história desta mulher na Assembleia Legislativa do Rio Grande do Sul, além de suas lutas específicas, é a sua presença como mulher e a nova relação que esta presença, per si, provocou. Suely pode não ter sido levada a sério pelos seus colegas homens, mas eles não podiam não ouvi-la, mesmo a chamando de nervosa, e isso reatualizava o campo.

A participação de Suely no parlamento gaúcho reafirma a importância da presença, tanto pela perspectiva que trouxe como mulher como pela reação que provocou. Por mais que Suely tenha sido ignorada, ou não tomada em consideraçáo, sua presença e sua força como mulher e como representante do funcionalismo público arranhavam, mesmo que de leve, as estruturas sexistas do campo político gaúcho.

\section{Referências bibliográficas}

ÁLVARES, Maria Luiza Miranda. Mulheres brasileiras em tempo de competiçáo eleitoral: seleçáo de candidaturas e degraus de acesso aos cargos parlamentares. DADOS - Revista de Ciências Sociais, Rio de Janeiro, v. 51, n. 4, p. 895-940, 2008.

ARAÚJO, Clara. Gênero e acesso ao poder legislativo no Brasil: as cotas entre as instituiçóes e a cultura. Revista Brasileira de Ciência Política, Brasília, n. 2, p. 23-59, jul./dez. 2009.

. Partidos políticos e gênero: mediaçóes nas rotas de ingresso das mulheres na representação política. Revista Sociologia e Politica, Curitiba, v. 24, p. 193-215, jun. 2005.

. Potencialidades e limites da política de cotas no Brasil. Revista de Estudos Feministas, Florianópolis, v. 9, n. 1, p. 231-252, 2001.

AVELAR, Lúcia. Mulheres na elite política brasileira: canais de acesso ao poder. São Paulo: Fundação Konrad Adenauer, 2001. 
BORGES, Ney. Depoimento. In: Divisão de Biblioteca e Memória Parlamentar (Coord.). Perfis parlamentares (v. 11) Suely de Oliveira. Perfil Biográfico. Depoimentos e discursos. Porto Alegre: Assembleia Legislativa do Rio Grande do Sul, 2007. p. 48-50.

BOURDIEU, Pierre. La Distinction. Paris: Les Éditions de Minuit, 1979.

. La Noblesse d'État. Paris: Les Editions de Minuit, 1989.

BUTLER, Judith. Problemas de gênero: Feminismo e subversão de identidades. Rio de Janeiro: Civilização Brasileira, 2012.

BUTLER, Judith; WEED, Elizabeth (Eds.). Question of gender. Bloomington: Indiana University Press, 2011.

FERREIRA, Aurélio Buarque de Hollanda. Novo Dicionário Eletrônico Aurélio versão 7.0.

HAGMANN, Lauro. Depoimento. In: Divisão de Biblioteca e Memória Parlamentar (Coord.). Perfis Parlamentares (v. 11) Suely de Oliveira. Perfil Biográfico. Depoimentos e discursos. Porto Alegre: Assembleia Legislativa do Rio Grande do Sul, 2007. p. 45-47.

HOFFMANN, Alberto. Depoimento. In: Divisão de Biblioteca e Memória Parlamentar (Coord.). Perfis parlamentares (v. 11) Suely de Oliveira. Perfil Biográfico. Depoimentos e discursos. Porto Alegre: Assembleia Legislativa do Rio Grande do Sul, 2007. p. 35-37.

IRIGARAY, Terezinha. Depoimento. In: Divisão de Biblioteca e Memória Parlamentar (Coord.). Perfis parlamentares (v. 11) Suely de Oliveira. Perfil Biográfico. Depoimentos e discursos. Porto Alegre: Assembleia Legislativa do Rio Grande do Sul, 2007. p. 58-60.

MIGUEL, Luis Felipe. Política de interesses, política do desvelo: representação e "singularidade feminina”. Estudos Feministas, Florianópolis, p. 253-267, jan. 2001.

Teoria política feminista e liberalismo: o caso das cotas de representação. Revista Brasileira de Ciências Sociais, v. 15, n. 44, p. 91-102, out. 2000.

MIGUEL, Luis Felipe; BIROLI, Flávia. Práticas de gênero e carreiras políticas: vertentes explicativas. Estudos Feministas, Florianópolis, v. 18, n. 3, p. 653-679, set./dez. 2010.

OLIVEIRA, Suely. Depoimento. In: Divisão de Biblioteca e Memória Parlamentar (Coord.). Perfis parlamentares (v. 11) Suely de Oliveira. Perfil Biográfico. Depoimentos e discursos. Porto Alegre: Assembleia Legislativa do Rio Grande do Sul, 2007. p. 61-274.

PARAGUASSU, Aluisio. Depoimento. In: Divisão de Biblioteca e Memória Parlamentar (Coord.). Perfis parlamentares (v. 11) Suely de Oliveira. Perfil Biográfico. Depoimentos e discursos. Porto Alegre: Assembleia Legislativa do Rio Grande do Sul, 2007. p. 38-40.

PHILLIPS, Anne. Equality, Difference. Public Representation. In: BENHABIB, Seyla. Democracy and Difference. Princeton: Princeton Press, 1996. p. 146.

RIBEIRO, Sybilla. Depoimento. In: Divisão de Biblioteca e Memória Parlamentar (Coord.). Perfis Parlamentares (v. 11) Suely de Oliveira. Perfil Biográfico. Depoimentos e discursos. Porto Alegre: Assembleia Legislativa do Rio Grande do Sul, 2007. p. 56-57. 
SASAK, Silvia. Smoking fetish: representaçōes femininas nas Propagandas de cigarro (19401960). Fazendo Gênero 9. Diásporas, Diversidades, Deslocamentos. 23-26 ago. 2010. Disponível em: <www.fazendogenero.ufsc.br/9/resources/anais/1277920551_ARQUIVO_ SmokingFetish_SilviaSasaki>. Acesso em: 13 dez. 2012.

TERLERA, João Carlos. Perfil de uma Pioneira. In: Perfis parlamentares (v. 11) Suely de Oliveira. Perfil Biográfico. Depoimentos e discursos. Porto Alegre: Assembleia Legislativa do Rio Grande do Sul, 2007. p. 23-27.

YOUNG, Iris. Inclusion and Democracy. Oxford: Oxford University Press, 2000.

On Female Body Experience. Oxford: Oxford University Press, 2005. 